\title{
A review of remote health monitoring based on internet of things
}

\author{
Omar AlShorman ${ }^{1}$, Buthaynah Alshorman ${ }^{2}$, Mahmoud Masadeh $^{3}$, Fahad Alkahtani $^{4}$, Basim Al-Absi ${ }^{5}$ \\ ${ }^{1}$ Faculty of Engineering and AlShrouk Trading Company, Najran University, Najran, Saudi Arabia \\ ${ }^{2}$ South Alternative Center for Physiotherapy and Rehabilitation, Najran, Saudi Arabia \\ ${ }^{3}$ Computer Engineering Department, Yarmouk University, Irbid, Jordan \\ ${ }^{4}$ Electrical Engineering Department, Faculty of Engineering, Najran University, Najran, Saudi Arabia \\ ${ }^{5}$ Computer Science Department, Najran University, Najran, Saudi Arabia
}

\begin{tabular}{l} 
Article Info \\
\hline Article history: \\
Received Dec 10, 2020 \\
Revised Feb 14, 2021 \\
Accepted Mar 4, 2021 \\
\hline
\end{tabular}

\section{Keywords:}

Diseases

Healthcare monitoring

IoT

Medical information

Sensors

\begin{abstract}
Managing, diagnosis, prognosis, continuous monitoring, early detection, and preventing chronic diseases for patients and elderly people have been gained a crucial role nowadays. However, elderly people with chronic health conditions such as diabetes, cardiovascular disease, and mental diseases, need special health care. With the help of the internet of things (IoT) technologies, remote health monitoring (RHM) helps patients, caregivers, and countries for improving healthcare services, such as medical files services, mobile healthcare (mhealth), telemedicine services, and sensing technology. Moreover, RHM aims to reduce hospitalized demands and costs. The main contribution of the proposed study is to review RHM studies based on IoT technologies. Moreover, the challenges and possible future trends of RMH are highlighted.
\end{abstract}

This is an open access article under the CC BY-SA license.

\section{Corresponding Author:}

Omar AlShorman

Faculty of Engineering, and AlShrouk Trading Company

Najran University, Najran, Saudi Arabia

E-mail: omar2007_ahu@yahoo.com

\section{INTRODUCTION}

Currently, elderly, and aging people are increasing globally [1]. According to the reports of the world health organization (WHO), 30 years from now, i.e., in 2050, the proportion of the world's elderly people, who are over 60 years old, will nearly double from $12 \%$ to $22 \%$ ( 2 billion). For example, nowadays, in Japan $30 \%$ of the population are already over 60 years old. This fact indicates a dangerous and important challenge for societies and countries [2]. However, real time and continuous disease monitoring lead to early detection of diseases and to increase the safety of the elderly people [3, 4].

Undoubtedly, elderly people with a chronic health condition, such as diabetes, cardiovascular disease, epilepsy, need special health care [5, 6]. Thus, remote health monitoring (RHM) can help patients, caregivers, and countries for improving healthcare services, such as medical file services, mobile healthcare (mhealth) telemedicine services, and sensing technology [7, 8]. Table 1 shows the importance and advantages of RHM [9, 10].

Recently, as a vision of the next generation of the healthcare industry [11], advanced trends in communication and technology aim to enhance healthcare and medical services [12, 13]. Internet of things (IoT) represents the revolution for the next technology era [14]. IoT aims to connect all healthcare objects, devices, services, and resources together using advanced networking technology [15]. Importantly, this application of the IoT is called internet of medical things (IoMT), which uses all medical connected resources to establish a medical 
information network [16]. This network can be used for remote healthcare monitoring (RHM), rehabilitation systems [17], disease diagnosis [18], prognosis [19], detection [20], management [21], prediction [22], and prevention [23]. Importantly, IoMT in RHM applications is used to collect remote patient's data (physiological and clinical measurements such as blood pressure, skin temperature, heart rate [24]) by smart connected devices and sensors over the network $[25,26]$. The collected data are then transferred to be stored and analyzed in the cloud computing systems [27, 28]. Figure 1 shows a health care monitoring framework based on IoT [29, 30], while Table 2 summarizes the main characteristics of all possible sensors that are used in RHM.

Table 1. The importance of remote health monitoring

\begin{tabular}{|c|c|c|c|}
\hline \multirow[b]{2}{*}{ The Term } & \multicolumn{3}{|c|}{ Importance Level } \\
\hline & For Patients & For Caregivers & For Countries \\
\hline Price & Less cost & Less cost & Cost-effective \\
\hline Comfortability & Comfort & Comfort and make less crowd & Provide better health care services \\
\hline Mobility & Solved & Comfort and make less crowd & Cost-effective and Avoid emergencies \\
\hline Continuity & Continuous & Continuous & Provide better health care services \\
\hline Speed & $\begin{array}{l}\text { Fast detection } \\
\text { of illnesses }\end{array}$ & $\begin{array}{l}\text { Fast detection } \\
\text { of illnesses }\end{array}$ & Provide better health care services \\
\hline Quality & Better & Better & Better \\
\hline Medical intervention & Early & Early & Avoid emergencies \\
\hline Tracking and monitoring & Real time and quick & Real time and quick & Provide better health care services \\
\hline Convenience & Better & Better & Provide better health care services \\
\hline Accessibility & Real time access & Real time access & Enhance treatment abilities \\
\hline Disease Management & Adequate & Less medical errors & Enhance treatment abilities \\
\hline Treatment accuracy & Better & Less medical errors & Enhance treatment abilities \\
\hline $\begin{array}{l}\text { Reliability and } \\
\text { availability }\end{array}$ & High & Real time and continuous & Enhance treatment abilities \\
\hline $\begin{array}{l}\text { Resource utilization of } \\
\text { medical centers }\end{array}$ & - & Less & $\begin{array}{l}\text { Less maintenance cost, less crowed, } \\
\text { and provide better health care services }\end{array}$ \\
\hline Disease diagnosis & Better & High data processing capabilities & Provide better health care services \\
\hline Rehabilitation services & $\begin{array}{l}\text { Continuous, reliable, and } \\
\text { fast }\end{array}$ & Accurate and remote monitoring & $\begin{array}{l}\text { Less cost and provide better health } \\
\text { care services }\end{array}$ \\
\hline $\begin{array}{l}\text { Duration time in medical } \\
\text { centers }\end{array}$ & Less & less cost and less crowed & less cost and less crowed \\
\hline $\begin{array}{l}\text { Collecting, processing, } \\
\text { and visualization data }\end{array}$ & Fast & Fast and high accuracy & Provide better health care services \\
\hline $\begin{array}{l}\text { Medical reporting and } \\
\text { decision making }\end{array}$ & Reliable & Smart & Enhance treatment abilities \\
\hline
\end{tabular}

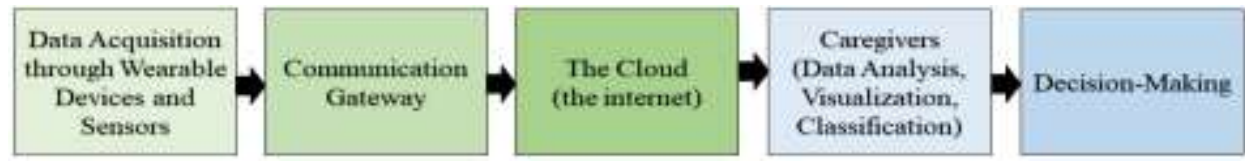

Figure 1. Health care monitoring framework based on IoT

Table 2. Sensing technologies used in RHM based on IoT

\begin{tabular}{|c|c|c|c|}
\hline Sensing technology & Usage & Application & References \\
\hline Electroencephalogram (EEG) & Brain signal activities & Mental diseases & {$[31,32]$} \\
\hline Electrocardiogram (ECG) & Heart signal activities & Heart diseases & [33] \\
\hline Electrooculography (EOG) & Ophthalmological diagnosis & Retinal disorders & [34] \\
\hline Electromyogram (EMG) & Muscle electrical activity & Muscles diseases & {$[35]$} \\
\hline Body temperature sensor & Body temperature measurement & Infection & [36] \\
\hline Blood pressure sensor & Blood pressure measurement & Hypertension & [37] \\
\hline Heart rate sensor & Heart monitoring & Heart diseases & [38] \\
\hline Respiration rate & Breathing and chest monitoring & Lung diseases & [39] \\
\hline Galvanic skin sensor & Skin conductance & Electrodermal activity & [40] \\
\hline Blood glucose sensor & Blood glucose measurement & Diabetes & [41] \\
\hline Oxygen level sensor & Blood-oxygen monitoring & Blood diseases & [42] \\
\hline Inertial sensor & Motion acceleration & Physical activity monitoring, tracking, and rehabilitation & [43] \\
\hline Location sensor & Human activity & Physical activity monitoring, tracking, and rehabilitation & [44] \\
\hline Camera sensor & Human activity & Physical activity monitoring, tracking, and rehabilitation & [45] \\
\hline
\end{tabular}

The prime contribution of the proposed work is to review RHM studies based on IoT technologies. Moreover, challenges and possible future trends are also highlighted. 


\section{RELATED WORK}

Explaining research chronological, including research design, research procedure (in the form of algorithms, Pseudocode or other), how to test and data acquisition [1-3]. The description of the course of research should be supported references, so the explanation can be accepted scientifically [2, 4].

Nowadays, IoT plays a vital role in RHM to reduce hospitalized demands and the cost [31, 32]. Also, RHM aims to enable an uninterrupted and real time observation for patients and elderly people in order to diagnose, manage, and prevent disease [46, 47]. That includes:

a) Diabetic patients [41]

b) Heart diseases [48]

c) Cardiovascular diseases [49]

d) Blood diseases [50]

e) Mental diseases [51]

f) Arthritis disease [52]

g) Fall detection and prediction [53]

h) Activity detection and recognition [54]

i) Medication Management [55]

j) Rehabilitation [56]

k) Personal Fitness monitoring [57]

Next, Table 3 summarizes well-known works the literature for RHM based on IoT, where the sensing technology and the main characteristics of each work are highlighted.

Table 3. RHM based IoT related literatures

\begin{tabular}{|c|c|c|c|c|}
\hline Literature & & Contribution & $\begin{array}{l}\text { Sensing } \\
\text { technology }\end{array}$ & Highlights \\
\hline$[60]$ & $\begin{array}{l}\text { RHM for cardiac based on } \\
\text { IoT }\end{array}$ & ECG & & $\begin{array}{l}\text { - Diagnosis of the heart disease } \\
\text { using ECG monitoring }\end{array}$ \\
\hline [61] & $\begin{array}{l}\text { Regular monitoring of } \\
\text { arthritis disease based on IoT }\end{array}$ & $\begin{array}{l}\text { Wearable sensor gadgets and uric } \\
\text { acid sensor }\end{array}$ & & $\begin{array}{l}\text { Diagnosis of joint } \\
\text { inflammation } \\
\text { - Joint pain illness and leg } \\
\text { movement monitoring are } \\
\text { recognized }\end{array}$ \\
\hline [63] & $\begin{array}{l}\text { IoT monitoring elderly } \\
\text { health and sleep patterns }\end{array}$ & $\begin{array}{l}\text { Wearable wrist-worn activity } \\
\text { sensor }\end{array}$ & & $\begin{array}{l}\text { Unobtrusive monitoring of } \\
\text { circadian activity and sleep } \\
\text { patterns } \\
\text { - Continuous monitoring of } \\
\text { physical activity }\end{array}$ \\
\hline [64] & $\begin{array}{l}\text { IoT based health care } \\
\text { monitoring and tracking } \\
\text { system }\end{array}$ & GPS and GSM & & $\begin{array}{l}\text { - Real time health monitoring } \\
\text { and tracking. }\end{array}$ \\
\hline [68] & IoT mental disorder tracking & Mobile cellular & & $\begin{array}{l}\text { - Tracking the patient in the } \\
\text { outdoor environment } \\
\text { - Scalability and power } \\
\text { efficiency }\end{array}$ \\
\hline
\end{tabular}




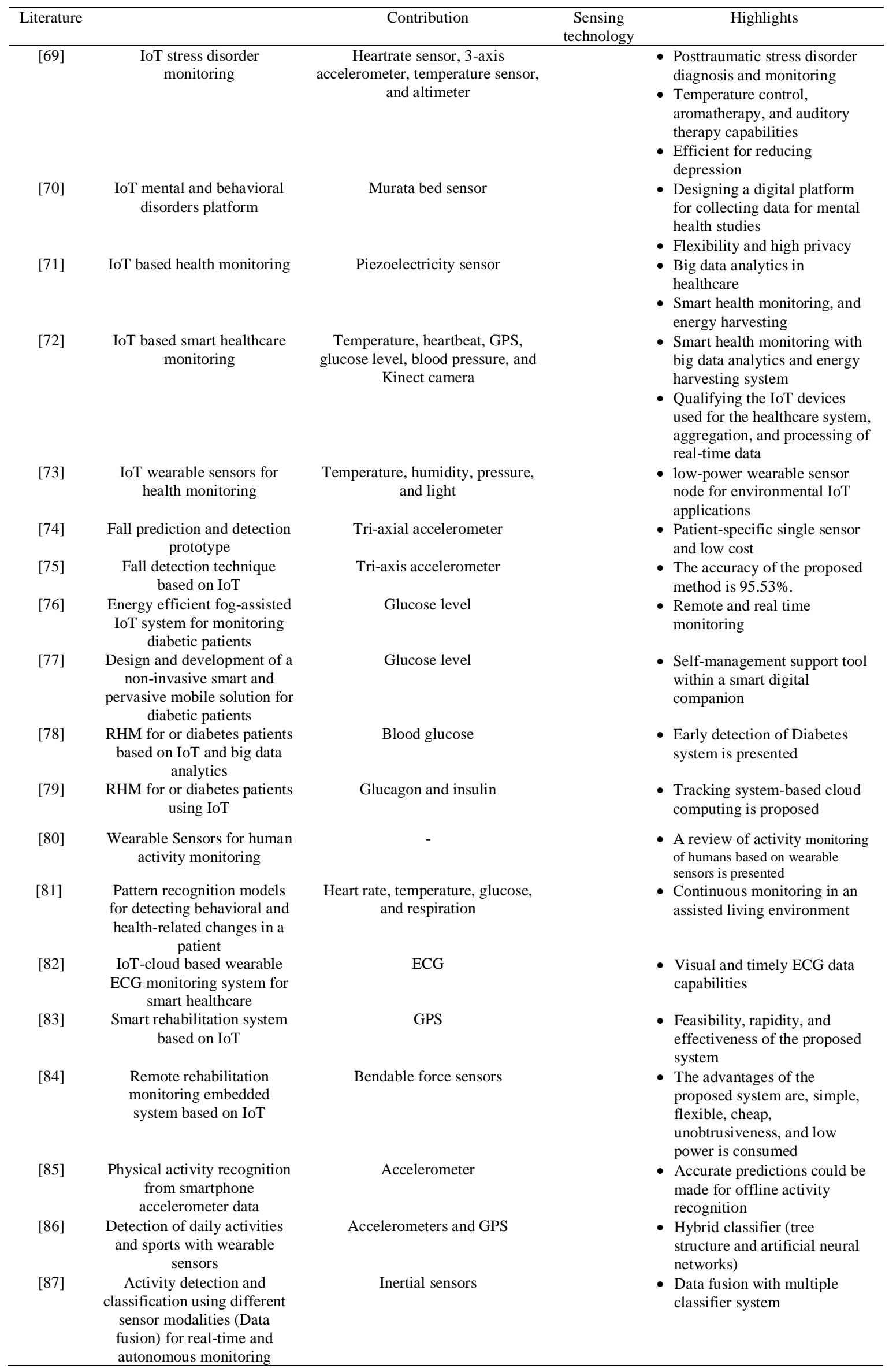




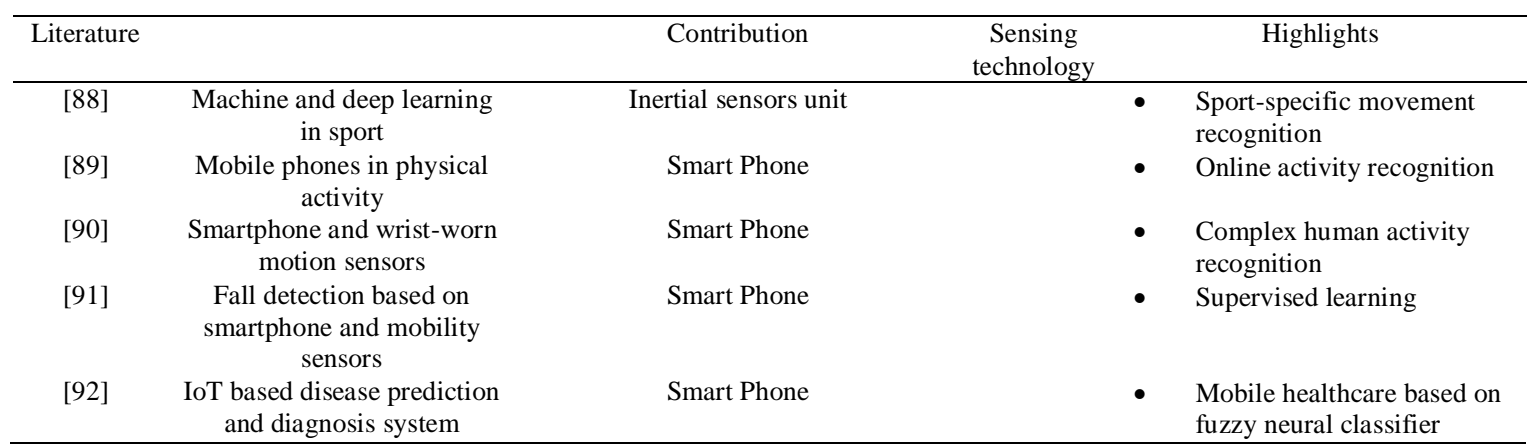

After studying and reviewing several studies about RHM based on IoT, it can be found that the proposed topic is considered as a hero nowadays and still in its infante stage. However, more efforts and contributions are still needed to tackle the callenges and gaps.

\subsection{Challenges and future trends}

This section summarizes the main challenges and the possible future trends for RHM based on IoT [93-109]:

a) Usability: patients and elderly people may not engage with sensors and recent technologies. Moreover, wearable sensor should be designed in comfortable shape for the wearer.

b) Cost: advanced sensors, security protocols, network infrastructure, and compatible systems may carry a huge cost.

c) Data Security: protecting patient's data from hacking and stolen is a challenging issue.

d) Integration and standardization: build a medical network with medical devices is a challenging task.

e) Data acquisition: noise, uncontrolled environment, sealing, sensor placement and position, and size of the sensor may lead to difficulties in data collecting.

f) Feature extraction: obtain valuable diagnostic information from wearable sensor data is very crucial. However, high accuracy and high-performance feature extraction methods should be developed.

g) Big data problem: real time and continous monitoring lead to produce huge mass of data. However, big data analytics and protocols have to be developed for dealing with huge mass of collected data, even approximately.

h) Safety: wearable sensors with batteries may lead to skin problems.

i) Power consumption: Sensors have a limited power capacity.

\section{CONCLUSIONS}

Currently, elderly and aging people are increasing globally. Thus, the use of novel advanced technology in healthcare industries has critically required to enhance medical services for those people. RHM with the help of IoT technologies offers remote and continuous monitoring for patients and elderly people. Moreover, RHM aims to enable a continuous and real time monitoring to diagnose, manage, and prevent disease. The proposed review study highlighted RHM based on IoT studies. Finally, challenges and future trends of this emerging topic are also discussed and highlighted.

\section{REFERENCES}

[1] L. A. Durán-Vega, P. C. Santana-Mancilla, R. Buenrostro-Mariscal, J. Contreras-Castillo, L. E. Anido-Rifón, M. A. García-Ruiz, et al., "An iot system for remote health monitoring in elderly adults through a wearable device and mobile application," Geriatrics, vol. 4, no. 2, p. 34, 2019, doi: 10.3390/geriatrics4020034.

[2] R. K. Pathinarupothi, P. Durga, and E. S. Rangan, "Iot-based smart edge for global health: Remote monitoring with severity detection and alerts transmission," IEEE Internet of Things Journal, vol. 6, no. 2, pp. 2449-2462, 2018, doi: 10.1109/JIOT.2018.2870068.

[3] F. Attal, S. Mohammed, M. Dedabrishvili, F. Chamroukhi, L. Oukhellou, and Y. Amirat, "Physical human activity recognition using wearable sensors," Sensors, vol. 15, no. 12, pp. 31314-31338, 2015, doi: 10.3390/s151229858.

[4] A. Alabdulatif, I. Khalil, A. R. M. Forkan, and M. Atiquzzaman, "Real-time secure health surveillance for smarter health communities," IEEE Communications Magazine, vol. 57, no. 1, pp. 122-129, 2018, doi: 10.1109/MCOM.2017.1700547.

[5] J. Evans, A. Papadopoulos, C. T. Silvers, N. Charness, W. R. Boot, L. Schlachta-Fairchild, et al., "Remote health monitoring for older adults and those with heart failure: adherence and system usability," Telemedicine and eHealth, vol. 22, no. 6, pp. 480-488, 2016, doi: 10.1089/tmj.2015.0140. 
[6] M. Shahidul Islam, M. T. Islam, A. F. Almutairi, G. K. Beng, N. Misran, and N. Amin, "Monitoring of the human body signal through the Internet of Things (IoT) based LoRa wireless network system," Applied Sciences, vol. 9, no. 9 , p. $1884,2019$.

[7] J. Qi, P. Yang, G. Min, O. Amft, F. Dong, and L. Xu, "Advanced internet of things for personalised healthcare systems: A survey," Pervasive and Mobile Computing, vol. 41, pp. 132-149, 2017, doi: 10.1016/j.pmcj.2017.06.018.

[8] S. Kim and S. Kim, "User preference for an IoT healthcare application for lifestyle disease management," Telecommunications Policy, vol. 42, no. 4, pp. 304-314, 2018, doi: 10.1016/j.telpol.2017.03.006.

[9] S. Majumder, T. Mondal, and M. J. Deen, "Wearable sensors for remote health monitoring," Sensors, vol. 17, no. 1, p. 130, 2017, doi: 10.3390/s17010130.

[10] S. R. Guntur, R. R. Gorrepati, and V. R. Dirisala, "Internet of Medical Things: Remote Healthcare and Health Monitoring Perspective," in Medical Big Data and Internet of Medical Things, ed: CRC Press, 2018, pp. 271-297.

[11] H. Mora, D. Gil, R. M. Terol, J. Azorín, and J. Szymanski, "An IoT-based computational framework for healthcare monitoring in mobile environments," Sensors, vol. 17, no. 10, p. 2302, 2017, doi: 10.3390/s17102302.

[12] M. M. Islam, A. Rahaman, and M. R. Islam, "Development of Smart Healthcare Monitoring System in IoT Environment," SN Computer Science, vol. 1, pp. 1-11, 2020, doi: 10.1007/s42979-020-00195-y.

[13] D. Dziak, B. Jachimczyk, and W. J. Kulesza, "IoT-based information system for healthcare application: design methodology approach," Applied sciences, vol. 7, no. 6, p. 596, 2017, doi: 10.3390/app7060596.

[14] H. Ahmadi, G. Arji, L. Shahmoradi, R. Safdari, M. Nilashi, and M. Alizadeh, "The application of internet of things in healthcare: a systematic literature review and classification," Universal Access in the Information Society, vol. 18, no. 4, pp. 837-869, 2019, doi: 10.1007/s10209-018-0618-4.

[15] K. Mohammed, A. Zaidan, B. Zaidan, O. Albahri, M. Alsalem, A. Albahri, et al., "Real-time remote-health monitoring systems: a review on patients prioritisation for multiple-chronic diseases, taxonomy analysis, concerns and solution procedure," Journal of medical systems, vol. 43, no. 7, p. 223, 2019, doi: 10.1007/s10916-019-1362-x.

[16] S. Anand and V. Nath, "Study and design of smart embedded system for remote health monitoring using internet of things," in Nanoelectronics, circuits and communication systems, ed: Springer, 2019, pp. 409-414, doi: 10.1007/978-981-13-0776-8_37.

[17] L. M. S. d. Nascimento, L. V. Bonfati, M. L. B. Freitas, J. J. A. Mendes Junior, H. V. Siqueira, and S. L. Stevan, "Sensors and Systems for Physical Rehabilitation and Health Monitoring-A Review," Sensors, vol. 20, no. 15, p. 4063, 2020, doi: 10.3390/s20154063.

[18] K. A. Al Mamun, M. Alhussein, K. Sailunaz, and M. S. Islam, "Cloud based framework for Parkinson's disease diagnosis and monitoring system for remote healthcare applications," Future Generation Computer Systems, vol. 66, pp. 36-47, 2017, doi: 10.1016/j.future.2015.11.010.

[19] P. Arpaia, C. Manna, G. Montenero, and G. D'Addio, "In-time prognosis based on swarm intelligence for homecare monitoring: A case study on pulmonary disease," IEEE Sensors Journal, vol. 12, no. 3, pp. 692-698, 2011, doi: 10.1109/JSEN.2011.2158305.

[20] A. Bansal, S. Kumar, A. Bajpai, V. N. Tiwari, M. Nayak, S. Venkatesan, et al., "Remote health monitoring system for detecting cardiac disorders," IET Systems Biology, vol. 9, pp. 309-314, 2015, doi: 10.1049/iet-syb.2015.0012.

[21] W. T. Abraham, "Disease management: remote monitoring in heart failure patients with implantable defibrillators, resynchronization devices, and haemodynamic monitors," Europace, vol. 15, pp. i40-i46, 2013, doi: 10.1093/europace/eut105.

[22] M. Yahyaie, M. J. Tarokh, and M. A. Mahmoodyar, "Use of internet of things to provide a new model for remote heart attack prediction," Telemedicine and e-Health, vol. 25, pp. 499-510, 2019, doi: 10.1089/tmj.2018.0076.

[23] V. Vijayakumar, D. Malathi, V. Subramaniyaswamy, P. Saravanan, and R. Logesh, "Fog computing-based intelligent healthcare system for the detection and prevention of mosquito-borne diseases," Computers in Human Behavior, vol. 100, pp. 275-285, 2019, doi:

[24] K. N. Swaroop, K. Chandu, R. Gorrepotu, and S. Deb, "A health monitoring system for vital signs using IoT," Internet of Things, vol. 5, pp. 116-129, 2019, doi: 10.1016/j.chb.2018.12.009.

[25] M. Al-Khafajiy, T. Baker, C. Chalmers, M. Asim, H. Kolivand, M. Fahim, et al., "Remote health monitoring of elderly through wearable sensors," Multimedia Tools and Applications, vol. 78, pp. 24681-24706, 2019, doi: 10.1007/s11042-018-7134-7.

[26] S. Majumder and M. J. Deen, "Smartphone sensors for health monitoring and diagnosis," Sensors, vol. 19, p. 2164, 2019, doi: $10.3390 / \mathrm{s} 19092164$.

[27] A. Subasi, L. Bandic, and S. M. Qaisar, "Cloud-based health monitoring framework using smart sensors and smartphone," in Innovation in Health Informatics, ed: Elsevier, 2020, pp. 217-243.

[28] F. Khan, A. Ghaffar, N. Khan, and S. H. Cho, "An Overview of Signal Processing Techniques for Remote Health Monitoring Using Impulse Radio UWB Transceiver," Sensors, vol. 20, p. 2479, 2020, doi: 10.3390/s20092479.

[29] C. A. Tokognon, B. Gao, G. Y. Tian, and Y. Yan, "Structural health monitoring framework based on Internet of Things: A survey," IEEE Internet of Things Journal, vol. 4, no. 3, pp. 619-635, 2017, doi: 10.1109/JIOT.2017.2664072.

[30] B. Farahani, F. Firouzi, V. Chang, M. Badaroglu, N. Constant, and K. Mankodiya, "Towards fog-driven IoT eHealth: Promises and challenges of IoT in medicine and healthcare," Future Generation Computer Systems, vol. 78, pp. 659-676, 2018, doi: 10.1016/j.future.2017.04.036.

[31] O. AlShorman, T. Ali, and M. Irfan, "EEG Analysis for Pre-learning Stress in the Brain," in Asian Simulation Conference, 2017, pp. 447-455, doi: 10.1007/978-981-10-6502-6_39. 
[32] O. M. AlShorman and A. M. Alshorman, "Frontal lobe and long-term memory retrieval analysis during prelearning stress using EEG signals," Bulletin of Electrical Engineering and Informatics, vol. 9, pp. 141-145, 2020, doi: 10.11591/eei.v9i1.1335.

[33] A. M. Koya and P. Deepthi, "Plug and play self-configurable IoT gateway node for telemonitoring of ECG," Computers in Biology and Medicine, vol. 112, p. 103359, 2019, doi: 10.1016/j.compbiomed.2019.103359.

[34] N. L. Viana, J. A. L. B. Junior, and F. A. Brito-Filho, "Micro-controlled EOG Device for Track and Control Military Applications," in Developments and Advances in Defense and Security, ed: Springer, 2020, pp. 149-157, doi: 10.1007/978-981-13-9155-2_13.

[35] S. Zhao, J. Liu, Z. Gong, Y. Lei, X. OuYang, C. C. Chan, et al., "Wearable Physiological Monitoring System Based on Electrocardiography and Electromyography for Upper Limb Rehabilitation Training," Sensors, vol. 20, p. 4861, 2020, doi: 10.3390/s20174861.

[36] N. H. Wijaya, A. G. Alvian, A. Z. Arfianto, J. E. Poetro, and F. Waseel, "Data Storage Based Heart and Body Temperature Measurement Device," Journal of Robotics and Control (JRC), vol. 1, no. 1, pp. 11-14, 2019, doi: 10.18196/jrc. 1103.

[37] S. Marathe, D. Zeeshan, T. Thomas, and S. Vidhya, "A Wireless Patient Monitoring System using Integrated ECG module, Pulse Oximeter, Blood Pressure and Temperature Sensor," in 2019 International Conference on Vision Towards Emerging Trends in Communication and Networking (ViTECoN), 2019, pp. 1-4, doi: 10.1109/ViTECoN.2019.8899541.

[38] R. A. Firmansyah and B. Guruh, "Monitoring Heart Rate And Temperature Based On The Internet Of Things," Journal of Electronics, Electromedical Engineering, and Medical Informatics, vol. 1, no. 2, pp. 1-7, 2019, doi: 10.35882/jeeemi.v1i2.1.

[39] S. T. U. Shah, F. Badshah, F. Dad, N. Amin, and M. A. Jan, "Cloud-assisted IoT-based smart respiratory monitoring system for asthma patients," in Applications of Intelligent Technologies in Healthcare, ed: Springer, 2019, pp. 77-86, doi: 10.1007/978-3-319-96139-2_8.

[40] P. P. Ray, D. Dash, and D. De, "Analysis and monitoring of IoT-assisted human physiological galvanic skin response factor for smart e-healthcare," Sensor Review, 2019, doi: 10.1108/SR-07-2018-0181.

[41] T. M. Fernández-Caramés, I. Froiz-Míguez, O. Blanco-Novoa, and P. Fraga-Lamas, "Enabling the internet of mobile crowdsourcing health things: A mobile fog computing, blockchain and IoT based continuous glucose monitoring system for diabetes mellitus research and care," Sensors, vol. 19, p. 3319, 2019, doi: $10.3390 / \mathrm{s} 19153319$

[42] K. Zhang and W. Ling, "Health Monitoring of Human Multiple Physiological Parameters Based on Wireless Remote Medical System," IEEE Access, vol. 8, pp. 71146-71159, 2020, doi: 10.1109/ACCESS.2020.2987058.

[43] K. H. Koh, Q. Shi, S. Cao, D. Ma, H. Y. Tan, Z. Guo, et al., "A self-powered 3D activity inertial sensor using hybrid sensing mechanisms," Nano energy, vol. 56, pp. 651-661, 2019, doi: 10.1016/j.nanoen.2018.11.075.

[44] E. Kanjo, E. M. Younis, and C. S. Ang, "Deep learning analysis of mobile physiological, environmental and location sensor data for emotion detection," Information Fusion, vol. 49, pp. 46-56, 2019, doi: 10.1016/j.inffus.2018.09.001

[45] A. Prati, C. Shan, and K. I.-K. Wang, "Sensors, vision and networks: From video surveillance to activity recognition and health monitoring," Journal of Ambient Intelligence and Smart Environments, vol. 11, no. 1, pp. 522, 2019, doi: 10.3233/AIS-180510.

[46] P. C. Santana-Mancilla, L. E. Anido-Rifón, J. Contreras-Castillo, and R. Buenrostro-Mariscal, "Heuristic evaluation of an IoMT system for remote health monitoring in senior care," International Journal of Environmental Research and Public Health, vol. 17, no. 5, p. 1586, 2020, doi: 10.3390/ijerph17051586.

[47] P. Singh, "Internet of things based health monitoring system: opportunities and challenges," International journal of advanced research in computer Science, vol. 9, no. 1, pp. 224-228, 2018, doi: 10.26483/ijarcs.v9i1.5308.

[48] M. A. Santos, R. Munoz, R. Olivares, P. P. Rebouças Filho, J. Del Ser, and V. H. C. de Albuquerque, "Online heart monitoring systems on the internet of health things environments: A survey, a reference model and an outlook," Information Fusion, vol. 53, pp. 222-239, 2020, doi: 10.1016/j.inffus.2019.06.004.

[49] F. Jabeen, M. Maqsood, M. A. Ghazanfar, F. Aadil, S. Khan, M. F. Khan, et al., "An IoT based efficient hybrid recommender system for cardiovascular disease," Peer-to-Peer Networking and Applications, vol. 12, pp. 12631276, 2019, doi: 10.1007/s12083-019-00733-3.

[50] F. Lamonaca, E. Balestrieri, I. Tudosa, F. Picariello, D. L. Carnì, C. Scuro, et al., "An overview on Internet of medical things in blood pressure monitoring," in 2019 IEEE International Symposium on Medical Measurements and Applications (MeMeA), 2019, pp. 1-6, doi: 10.1109/MeMeA.2019.8802164.

[51] I. de la Torre Díez, S. G. Alonso, S. Hamrioui, E. M. Cruz, L. M. Nozaleda, and M. A. Franco, "IoT-based services and applications for mental health in the literature," Journal of medical systems, vol. 43, no. 1, p. 11, 2019, doi: 10.1007/s10916-018-1130-3.

[52] M. W. Raad, M. A. Deriche, A. B. Hafeedh, H. Almasawa, K. B. Jofan, H. Alsakkaf, et al., "An IOT based Wearable Smart Glove for Remote Monitoring of Rheumatoid Arthritis Patients," in BIOSIGNALS, 2019, pp. 224228, doi: 10.5220/0007573302240228.

[53] N. Mozaffari, J. Rezazadeh, R. Farahbakhsh, S. Yazdani, and K. Sandrasegaran, "Practical fall detection based on IoT technologies: A survey," Internet of Things, vol. 8, p. 100124, 2019, doi: 10.1016/j.iot.2019.100124.

[54] V. Bianchi, M. Bassoli, G. Lombardo, P. Fornacciari, M. Mordonini, and I. De Munari, "IoT wearable sensor and deep learning: An integrated approach for personalized human activity recognition in a smart home environment," IEEE Internet of Things Journal, vol. 6, no. 5, pp. 8553-8562, 2019, doi: 10.1109/JIOT.2019.2920283. 
[55] A. Jagtap, A. Chougule, S. Pujari, A. Khamkar, and G. Machhale, "Intelligent Medicine Box for Medication Management Using Internet-of Things," in ICDSMLA 2019, ed: Springer, 2020, pp. 139-143, doi: 10.1007/978981-15-1420-3_15.

[56] A. Celesti, A. Lay-Ekuakille, J. Wan, M. Fazio, F. Celesti, A. Romano, et al., "Information management in IoT cloud-based tele-rehabilitation as a service for smart cities: Comparison of NoSQL approaches," Measurement, vol. 151, p. 107218, 2020, doi: 10.1016/j.measurement.2019.107218.

[57] B. Yong, Z. Xu, X. Wang, L. Cheng, X. Li, X. Wu, et al., "IoT-based intelligent fitness system," Journal of Parallel and Distributed Computing, vol. 118, pp. 14-21, 2018, doi: 10.1016/j.jpdc.2017.05.006.

[58] S. Tuli, N. Basumatary, S. S. Gill, M. Kahani, R. C. Arya, G. S. Wander, et al., "HealthFog: An ensemble deep learning based Smart Healthcare System for Automatic Diagnosis of Heart Diseases in integrated IoT and fog computing environments," Future Generation Computer Systems, vol. 104, pp. 187-200, 2020.

[59] S. S. Kazi, G. Bajantri, and T. Thite, "Remote Heart Rate Monitoring System Using IoT," Techniques for Sensing Heartbeat Using IoT, vol. 5, 2018.

[60] U. Maji, R. Mandal, S. Bhattacharya, and S. Priya, "An IoT-Based Remote Health Monitoring System for Smart Healthcare: Cardiac Health Monitoring-Based Approach," in Advancements in Instrumentation and Control in Applied System Applications, ed: IGI Global, 2020, pp. 231-254, doi: 10.4018/978-1-7998-8052-3.ch024.

[61] P. Parthasarathy and S. Vivekanandan, "A typical IoT architecture-based regular monitoring of arthritis disease using time wrapping algorithm," International Journal of Computers and Applications, vol. 42, no. 3, pp. 222-232, 2020, doi: 10.1080/1206212X.2018.1457471.

[62] D. Naranjo-Hernández, L. M. Roa, J. Reina-Tosina, and M. A. Estudillo-Valderrama, "SoM: a smart sensor for human activity monitoring and assisted healthy ageing," IEEE transactions on biomedical engineering, vol. 59, pp. 3177-3184, 2012, doi: 10.1109/TBME.2012.2206384.

[63] J. Merilahti, P. Viramo, and I. Korhonen, "Wearable monitoring of physical functioning and disability changes, circadian rhythms and sleep patterns in nursing home residents," IEEE journal of biomedical and health informatics, vol. 20, no. 3, pp. 856-864, 2016, doi: 10.1109/JBHI.2015.2420680.

[64] S. Fatima and A. Sayeed, "IOT based health care monitoring and tracking system using GPS and GSM Technologies," Int J Prof Eng Stud, vol. 8, p. 2017, 2017.

[65] H. Adardour, M. Hadjila, S. Irid, T. Baouch, and S. Belkhiter, "Outdoor Alzheimer's Patients Tracking Using an IoT System and a Kalman Filter Estimator," Wireless Personal Communications, pp. 1-17, 2020, doi: 10.1007/s11277-020-07713-4.

[66] A. Chávez, G. Borrego, J. O. Gutierrez-Garcia, and L.-F. Rodríguez, "Design and evaluation of a mobile application for monitoring patients with Alzheimer's disease: A day center case study," International Journal of Medical Informatics, vol. 131, p. 103972, 2019, doi: 10.1016/j.ijmedinf.2019.103972.

[67] J.-C. Kim and K. Chung, "Depression index service using knowledge based crowdsourcing in smart health," Wireless Personal Communications, vol. 93, pp. 255-268, 2017, doi: 10.1007/s11277-016-3923-3.

[68] N. Hayati and M. Suryanegara, "The IoT LoRa system design for tracking and monitoring patient with mental disorder," in 2017 IEEE International Conference on Communication, Networks and Satellite (Comnetsat), 2017, pp. 135-139, doi: 10.1109/COMNETSAT.2017.8263587.

[69] J. McWhorter, L. Brown, and L. Khansa, "A wearable health monitoring system for posttraumatic stress disorder," Biologically inspired cognitive architectures, vol. 22, pp. 44-50, 2017, doi: 10.1016/j.bica.2017.09.004.

[70] T. Aledavood, A. M. T. Hoyos, T. Alakörkkö, K. Kaski, J. Saramäki, E. Isometsä, et al., "Data collection for mental health studies through digital platforms: requirements and design of a prototype," JMIR research protocols, vol. 6 , p. e110, 2017, doi: 10.2196/resprot.6919.

[71] M. Babar, A. Rahman, F. Arif, and G. Jeon, "Energy-harvesting based on internet of things and big data analytics for smart health monitoring," Sustainable Computing: Informatics and Systems, vol. 20, pp. 155-164, 2018, doi: 10.1016/j.suscom.2017.10.009.

[72] S. Din and A. Paul, "Smart health monitoring and management system: toward autonomous wearable sensing for internet of things using big data analytics," Future Generation Computer Systems, vol. 91, pp. 611-619, 2019, doi: 10.1016/j.future.2017.12.059.

[73] F. Wu, C. Rüdiger, J.-M. Redouté, and M. R. Yuce, "A wearable multi-sensor IoT network system for environmental monitoring," in Advances in Body Area Networks I, ed: Springer, 2019, pp. 29-38.

[74] W. Saadeh, S. A. Butt, and M. A. B. Altaf, "A patient-specific single sensor IoT-based wearable fall prediction and detection system," IEEE transactions on neural systems and rehabilitation engineering, 2019, doi: 10.1109/TNSRE.2019.2911602.

[75] I. Chandra, N. Sivakumar, C. B. Gokulnath, and P. Parthasarathy, "IoT based fall detection and ambient assisted system for the elderly," Cluster Computing, vol. 22, pp. 2517-2525, 2019, doi: 10.1007/s10586-018-2329-2.

[76] T. N. Gia, I. B. Dhaou, M. Ali, A. M. Rahmani, T. Westerlund, P. Liljeberg, et al., "Energy efficient fog-assisted IoT system for monitoring diabetic patients with cardiovascular disease," Future Generation Computer Systems, vol. 93, pp. 198-211, 2019, doi: 10.1016/j.future.2018.10.029.

[77] L. Nguyen, S. Adibi, and N. Wickramasinghe, "Towards a Better Life for Diabetic Patients: Developing and Integrating a Non-invasive Self-Management Support Tool Within a Smart Digital Companion," in Delivering Superior Health and Wellness Management with IoT and Analytics, ed: Springer, 2020, pp. 207-222, doi: 10.1007/978-3-030-17347-0_10. 
[78] A. Rghioui, A. Naja, and A. Oumnad, "Diabetic Patients Monitoring and Data Classification Using IoT Application," in 2020 International Conference on Electrical and Information Technologies (ICEIT), 2020, pp. 1-6, doi: 10.1109/ICEIT48248.2020.9113171.

[79] C. Krishna and T. Sasikala, "Home Based Healthcare Monitoring System for Diabetes Patients Using IoT," in International Conference on Intelligent Data Communication Technologies and Internet of Things, 2018, pp. 676686, doi: 10.1007/978-3-030-03146-6_76.

[80] S. C. Mukhopadhyay, "Wearable sensors for human activity monitoring: A review," IEEE sensors journal, vol. 15, no.3, pp. 1321-1330, 2015, doi: 10.1109/JSEN.2014.2370945.

[81] A. R. M. Forkan, I. Khalil, Z. Tari, S. Foufou, and A. Bouras, "A context-aware approach for long-term behavioural change detection and abnormality prediction in ambient assisted living," Pattern Recognition, vol. 48, pp. 628-641, 2015, doi: 10.1016/j.patcog.2014.07.007.

[82] Z. Yang, Q. Zhou, L. Lei, K. Zheng, and W. Xiang, "An IoT-cloud based wearable ECG monitoring system for smart healthcare," Journal of medical systems, vol. 40, no.12, p. 286, 2016, doi: 10.1007/s10916-016-0644-9.

[83] Y. J. Fan, Y. H. Yin, L. Da Xu, Y. Zeng, and F. Wu, "IoT-based smart rehabilitation system," IEEE transactions on industrial informatics, vol. 10, pp. 1568-1577, 2014, doi: 10.1109/TII.2014.2302583.

[84] M. Rossi, A. Rizzi, L. Lorenzelli, and D. Brunelli, "Remote rehabilitation monitoring with an IoT-enabled embedded system for precise progress tracking," in 2016 IEEE International Conference on Electronics, Circuits and Systems (ICECS), 2016, pp. 384-387, doi: 10.1109/ICECS.2016.7841213.

[85] J. Wannenburg and R. Malekian, "Physical activity recognition from smartphone accelerometer data for user context awareness sensing," IEEE Transactions on Systems, Man, and Cybernetics: Systems, vol. 47, pp. 31423149, 2017, doi: 10.1109/TSMC.2016.2562509.

[86] M. Ermes, J. Pärkkä, J. Mäntyjärvi, and I. Korhonen, "Detection of daily activities and sports with wearable sensors in controlled and uncontrolled conditions," IEEE transactions on information technology in biomedicine, vol. 12, pp. 20-26, 2008, doi: 10.1109/TITB.2007.899496.

[87] H. F. Nweke, Y. W. Teh, G. Mujtaba, and M. A. Al-Garadi, "Data fusion and multiple classifier systems for human activity detection and health monitoring: Review and open research directions," Information Fusion, vol. 46, pp. 147-170, 2019, doi: 10.1016/j.inffus.2018.06.002.

[88] E. E. Cust, A. J. Sweeting, K. Ball, and S. Robertson, "Machine and deep learning for sport-specific movement recognition: a systematic review of model development and performance," Journal of sports sciences, vol. 37, no. 5, pp. 568-600, 2019, doi: 10.1080/02640414.2018.1521769.

[89] M. Shoaib, S. Bosch, O. Incel, H. Scholten, and P. Havinga, "A survey of online activity recognition using mobile phones," Sensors, vol. 15, pp. 2059-2085, 2015, doi: 10.3390/s150102059.

[90] M. Shoaib, S. Bosch, O. Incel, H. Scholten, and P. Havinga, "Complex human activity recognition using smartphone and wrist-worn motion sensors," Sensors, vol. 16, p. 426, 2016, doi: 10.3390/s16040426.

[91] J. Santoyo-Ramón, E. Casilari, and J. Cano-García, "Analysis of a smartphone-based architecture with multiple mobility sensors for fall detection with supervised learning," Sensors, vol. 18, p. 1155, 2018, doi: $10.3390 / \mathrm{s} 18041155$.

[92] P. M. Kumar, S. Lokesh, R. Varatharajan, G. C. Babu, and P. Parthasarathy, "Cloud and IoT based disease prediction and diagnosis system for healthcare using Fuzzy neural classifier," Future Generation Computer Systems, vol. 86, pp. 527-534, 2018, doi: 10.1007/978-981-15-4112-4_2.

[93] Y. Wang, L. Kung, and T. A. Byrd, "Big data analytics: Understanding its capabilities and potential benefits for healthcare organizations," Technological Forecasting and Social Change, vol. 126, pp. 3-13, 2018, doi: 10.1016/j.techfore.2015.12.019.

[94] M. Masadeh, O. Hasan and S. Tahar, "Input-Conscious Approximate Multiply-Accumulate (MAC) Unit for Energy-Efficiency," in IEEE Access, vol. 7, pp. 147129-147142, 2019, doi: 10.1109/ACCESS.2019.2946513.

[95] A. M. Rahmani, T. N. Gia, B. Negash, A. Anzanpour, I. Azimi, M. Jiang, et al., "Exploiting smart e-Health gateways at the edge of healthcare Internet-of-Things: A fog computing approach," Future Generation Computer Systems, vol. 78, pp. 641-658, 2018, doi: 10.1016/j.future.2017.02.014.

[96] L. M. R. Tarouco, L. M. Bertholdo, L. Z. Granville, L. M. R. Arbiza, F. Carbone, M. Marotta, et al., "Internet of Things in healthcare: Interoperatibility and security issues," in 2012 IEEE international conference on communications (ICC), 2012, pp. 6121-6125, doi: 10.1109/ICC.2012.6364830.

[97] V. Vippalapalli and S. Ananthula, "Internet of things (IoT) based smart health care system," in 2016 International Conference on Signal Processing, Communication, Power and Embedded System (SCOPES), 2016, pp. 1229-1233.

[98] A. M. Alshorman, O. Alshorman, M. Irfan, A. Glowacz, F. Muhammad, and W. Caesarendra, "Fuzzy-Based FaultTolerant Control for Omnidirectional Mobile Robot," Machines, vol. 8, p. 55, 2020, doi: 10.3390/machines8030055.

[99] O. AlShorman, B. AlShorman, M. Alkhassaweneh, F. Alkahtani, "A Review of Internet of Medical Things (IoMT) - Based Remote Health Monitoring through Wearable Sensors: A Case Study for Diabetic Patients, " Indonesian Journal of Electrical Engineering and Computer Science (IJEECS), vol. 20, no. 1, PP. 414-422, 2020.

[100] O. AlShorman, B. Alshorman, F. Alkahtani, "A review of wearable sensors based monitoring with daily physical activity to manage type 2 diabetes, “International Journal of Electrical and Computer Engineering (IJECE), vol.11, no. 1, 2021, pp. 2088-8708, 2021, doi: 10.11591/ijece.v11i1.pp646-653.

[101] M. Al-khassaweneh and O. AlShorman, "Frei-Chen Bases Based Lossy Digital Image Compression Technique," Applied Computing and Informatics, 2020, doi: 10.1016/j.aci.2019.12.004.

[102] Omar Al-Shorman."Lossy digital image compression technique using run-length encoding and Frei-Chen basis," Masters' thesis, Yarmouk University, 2012, doi: 10.1016/j.aci.2019.12.004. 
[103] O. AlShorman, B. Alshorman and M. Masadeh, "A Review of Physical Human Activity Recognition Chain Using Sensors", Indonesian Journal of Electrical Engineering and Informatics (IJEEI), vol 8, no 3, pp. 560-573, 2020, doi: 10.3390/s151229858.

[104] Bayrakdar, Muhammed Enes. "Priority based health data monitoring with IEEE 802.11 af technology in wireless medical sensor networks," Medical \& Biological Engineering \& Computing, vol. 57, no. 12, 2019, pp. 2757-2769, doi: 10.1007/s11517-019-02060-4.

[105] Bayrakdar, Muhammed Enes. "Fuzzy logic based coordinator node selection approach in wireless medical sensor networks," In 2019 4th International Conference on Computer Science and Engineering (UBMK), pp. 340-343. IEEE, 2019, doi: 10.1109/UBMK.2019.8907097.

[106] A Çalhan, "Energy Harvesting Unit Design for Body Area Networks", Sakarya University Journal of Computer and Information Sciences, vol. 2, no. 1, pp. 41-52, 2019, doi: 10.35377/saucis.02.01.512210.

[107] M. Masadeh, O. AlShorman, and A. R. Alhawari, "A Machine Learning-based Error Model for Quality Control of Functional Approximate Computing," in 2020 International Conference on Data Analytics for Business and Industry: Way Towards a Sustainable Economy (ICDABI), 2020, pp. 1-5, doi: 10.1109/ICDABI51230.2020.9325594.

[108] B. Guragai, O. AlShorman, M. Masadeh, and M. B. B. Heyat, "A survey on deep learning classification algorithms for motor imagery," in 2020 32nd International Conference on Microelectronics (ICM), 2020, pp. 1-4, doi: 10.1109/ICM50269.2020.9331503.

[109] O. AlShorman, "medical image compression technique for telemedicine applications," ARPN Journal of Engineering and Applied Sciences, vol. 15, no. 18, 2020. 